\title{
Experiência com dois tipos de técnicas para o tratamento cirúrgico da insuficiência mitral: I. Prótese com preservação de elementos do sistema valvar. II. Plastia valvar com reconstrução e avanço da cúspide posterior
}

Paulo Roberto Barbosa ÉVORA*; Paulo José de Freitas RIBEIRO*; José Carlos Franco BRASIL*; Adonis Garcia OTAVIANO*; Celso Luis dos REIS*; Hércules Lisboa BONGIOVANI*; Rúbio BOMBONATO*; Marcus Antônio FEREZ*; Antônio Carlos MENARDI; Ricardo Nilsson SGARBIERI*

ÉVORA, P. R. B.; RIBEIRO, P. J. F.; BRASIL, J. C. F.; OTAVIANO, A. G.; REIS, C. L.; BONGIOVANI, H. L.; BOMBONATO, R.; FEREZ, M. A.; MENARDI, A. C.; SGARBIERI, R. N. - Experiência com dois tipos de técnicas para o tratamento cirúrgico da insuficiência mitral: I. Prótese com preservação de elementos do sistema valvar. II. Plastia valvar com reconstrução e avanço da cúspide posterior. Rev. Bras. Cir. Cardiovasc., 3(1): 36-49, 1988

RESUMO: Na integridade funcional do ventriculo esquerdo, é importante a continuidade entre a valva mitral e a parede ventricular mantida pelas cordas tendíneas e os músculos papilares. Por outro lado, além de maior mortalidade cirúrgica da insuficiência mitral, quando comparada com as próteses aórticas e a revascularização do miocárdio, observa-se menor morbi-mortalidade nos casos de valvoplastias em relação às próteses mitrais. Estes fatos constituem um desafio para a moderna cirurgia cardiaca, justificando-se todos os esforços de ampliação dos estudos no tratamento do refluxo valvar, tanto pelas correçōes plásticas, como pelo implante de prótese. No presente trabalho, apresenta-se a experiência com dois tipos de técnicas para o tratamento cirúrgico da insuficiência mitral: prótese com preservação de elementos do sistema valvar e plastia valvar com ampliação e avanço da cúspide posterior. Preocupou-se mais com os detalhes cirúrgicos, não tendo sido realizados estudos da função ventricular esquerda. Apresentam-se as diversas táticas para garantir a continuidade entre $o$ anel valvar e parede do ventrículo nas trocas valvares. Ressalta-s a importância, nem sempre lembrada, da ampliaçāo da cúspide posterior e a sua associação com outras técnicas de plastias valvares, tais como: comissurotomias, papilarotomias, anuloplatias e encurtamento de cordas tendineas. cirurgia

DESCRITORES: insuficiência mitral, cirurgia; valvas cardiacas, cirurgia; próteses valvulares cardiacas,

\section{INTRODUÇĀO}

A mortalidade, nos casos de cirurgia da valva mitral, diminuiu de 18 a $40 \%$ na década de 1960 , para, aproxi- madamente, $10 \%$ no início da década de $1980^{10,14,15}$ 21, $40,47,52,53$, permanecendo em torno de $5 \%$ nos dias atuais $^{10}$. Esta significativa diminuiçāo da mortalidade deveu-se aos avanços tecnológicos e ao aperfeiçoamento

Trabalho realizado no Hospital do Coração de Ribeirăo Preto. Fundação Waldemar B. Pessoa. Ribeirăo Preto, SP, Brasil.

Apresentado ao 15: Congresso Nacional de Cirurgia Cardiaca. Rio de Janeiro, RJ, 7 e 8 de abril, 1988.

- Do Hospital do Coraçâo de Ribeirāo Preto. Fundaçāo Waldemar B. Pessoa.

Endereço para separatas: Paulo Roberto Évora. Rua Rui Barbosa, 455, Apto. 140. 14.015 Ribeiråo Preto, SP, Brasil. 
ÉVORA, P. R. B.; RIBEIRO, P. J. F.; BRASIL, J. C. F.; OTAVIANO, A. G.; REIS, C. L.; BONGIOVANI, H. L.; BOMBONATO, R.; FEREZ, M. A.; MENARDI, A. C.; SGARBIERI, R. N. - Experiência com dois tipos de técnicas para o tratamento cirúrgico da insuficiência mitral: I. Prótese com preservação de elementos do sistema valvar. II. Plastia valvar com reconstrução e avanço da cúspide posterior. Rev. Bras. Cir. Cardiovasc., 3(1): 36-49, 1988.

das técnicas cirúrgicas e de proteção ao miocárdio isquêmico. Porém, quando se comparam os resultados obtidos com a revascularizaçāo do miocárdio e as trocas valvares aórticas, observa-se que não foi possivel reduzir a mortalidade da cirurgia valvar mitral ${ }^{8,13}$, fato que constitui um desafio para a moderna cirurgia cardíaca.

Nas trocas mitrais, usualmente, os músculos papilares são seccionados e, muitas vezes, os pacientes tendem a apresentar, ou apresentam, síndrome de baixo débito cardíaco, que, na maioria dos casos, constitui a maior causa de mortalidade per-operatória. Por outro lado, a experiência internacional revela menor morbimortalidade nos casos de valvoplastias, quando comparada com as trocas valvares $5,6,7,21,27,30,41,42,49,54$. Além disso, existem evidências de que a melhora sintomática, após a substituição valvar, nos casos de insuficiência crônica, parece relacionar-se mais com um aumento do volume sistólico melhorando o débito cardíaco, do que com uma real recuperação da função ventricular esquerda $20,28,36$. Estes fatos evidenciam a importância da continuidade entre a valva mitral e a parede do ventriculo esquerdo, mantida pelas cordas tendíneas e os músculos papilares, na integridade funcional do ventrículo ${ }^{44}$. 45, 53. Justifica-se, portanto, a manutençāo do aparelho subvalvar na correção do refluxo por meio de valvoplastias $^{6,27}$ e, na impossibilidade destas, procurar substituir o conceito de "troca valvar" por "implante valvar". Estas perspectivas foram iniciadas por LILLEHEI $^{31}$, em 1962 , e divulgadas, extensivamente, pela escola canadense ${ }^{15-18}$. Nestes implantes valvares, os músculos papilares e as cordas tendíneas sảo preservados, conservando-se, dentro do possível, a "geometria" do ventrículo esquerdo. É interessante notar que se passaram quase 20 anos, desde que Lillehei propôs as trocas valvares com preservação dos músculos papilares e cordas tendíneas, até que HETZER ${ }^{25}$, MILLER $^{34}$, DAVID ${ }^{18}$ e MIKI ${ }^{33}$ passaram a considerá-las como técnicas fundamentais para a preservação da função ventricular esquerda. Este método, provavelmente, não foi utilizado de maneira mais ampla, pelo fato de a preservação das cordas tendíneas interferir com a função das próteses de bola ${ }^{33}$.

As valvoplastias ficam dificultadas, ou mesmo impossibilitadas, quando há retração ou destruiçāo da cúspides mitrais. Com freqüência, o cirurgião encontra insuficiências mitrais com cúspide anterior preservada e retração da cúspide posterior, o que, em geral, leva à utilizaçăo de próteses valvulares. Como se justificam todos os esforços para restaurar uma valva cardiaca doente, tendo em vista os inconvenientes das próteses, a plastia mitral por avanço da cúspide posterior foi proposta por SAUVAGE ${ }^{48}$, em 1963, que ampliou seus estudos por 3 anos ${ }^{46,47}$. Esta técnica foi utilizada, entre nós, por SADER*, na década de 1970 , e hoje é utilizada com freqüência por um dos autores (P.J.F.R.), que adaptou

- SADER, A. A. - Comunicaçăo pessoal, 1975. a correção cirúrgica com avanço da cúspide posterior mitral a outros detalhes técnicos das modernas plastias valvares ${ }^{45}$

No presente trabalho, apresenta-se uma experiência com as duas técnicas para o tratamento cirúrgico da insuficiência mitral: prótese com preservação de elementos do sistema valvar e plastia'valvar com avanço da cúspide posterior, associada ou não a outras manobras plásticas. O trabalho preocupa-se apenas com os aspectos técnico-cirúrgicos, sem a realização de estudos funcionais.

\section{MATERIAL E MÉTODOS}

Todos os pacientes foram submetidos a técnicas anestésicas padronizadas, utilizando-se, principalmente, fentanil, brometo de pancurônio, halotano e ventilação controlada. As cirurgias foram realizadas com auxílio de circulação extracorpórea, hipotermia sistêmica a $28^{\circ} \mathrm{C}$, proteção miocárdica por criocardioplegia cristalóide e soro gelado no pericárdio.

Os pacientes foram separados em 2 grupos, conforme a técnica utilizada para a correção do refluxo mitral: prótes com preservação de elementos do sistema valvar (Grupo A) e plastia valvar com ampliação e avanço da cúspide posterior (Grupo B).

\section{Grupo A}

No período de outubro de 1985 a dezembro de 1987 , realizaram-se 23 implantes de próteses mitrais, em 14 mulheres $(60,90 \%)$ e 9 homens $(39,30 \%)$ com idade de $38,13 \pm 14,18$ anos e pertencentes às classes funcionais III $(87,00 \%)$ e IV $(13,00 \%)$ da NYHA. As técnicas utilizadas de preservação do aparelho valvar foram: a) fixação do topo dos músculos papilares no anel posterior (Figura 1); b) fixação dos músculos papilares e cordas tendíneas no anel posterior (Figura 2); c) excisão parcial apenas da cúspide anterior, com fixação de seus papilares e cordas tendíneas, conservando-se os elementos valvares da cúspide posterior (Figura 3); d) conservação de todo o aparelho valvar (Figura 4). As próteses foram implantadas com pontos separados de poliéster 00 , em $\mathrm{U}$ ou em "chuleio", quando houve a necessidade de "acolchoar" possiveis excessos ou irregularidades do anel valvar. Algumas vezes, por medida de segurança, os pontos foram ancorados em pequenos selos de $\mathrm{Te}$ flon, que permaneciam em posição ventricular junto ao anel valvar. Na maioria dos casos, a via de acesso cirúrgico fez-se por toracotomia ântero-lateral no quarto espaço intercostal direito, utilizando-se esternotomia mediana, no caso de lesões associadas da valva aórtica. Os pacientes portadores de prótese metálica tiveram alta 
ÉVORA, P. R. B.; RIBEIRO, P. J. F.; BRASIL, J. C. F.; OTAVIANO. A. G.; REIS, C. L.; BONGIOVANI, H. L.; BOMBONATO, R.; FEREZ, M. A.; MENARDI, A. C.; SGARBIERI, R. N. - Experiência com dois tipos de técnicas para o tratamento cirúrgico da insuficiência mitral: I. Prótese com preservação de elementos do sistema valvar. II. Plastia valvar com reconstruçāo e avanço da cúspide posterior. Rev. Bras. Cir. Cardiovasc., 3(1): 36-49, 1988.

TABELA 1 CARACTERISTICAS INDIVIDUAIS DOS PACIENTES DO GRUPO A (PRÓTESE MITRAL COM PRESERVAÇÃO DE ELEMENTOS DO APARELHO VALVAR)

\begin{tabular}{|c|c|c|c|c|c|c|c|c|}
\hline CASO & INICIAIS & $I D A D E$ & SEXO & $\begin{array}{c}\text { GRAU FUNC. } \\
\text { (NYHA) }\end{array}$ & $T P(M I N)$ & TAO (MIN) & $\begin{array}{c}\text { ALTA HOSPIT. } \\
\text { (DIA) }\end{array}$ & TÉCNICA CIRÚRG. \\
\hline 1 & M.C.S. & 26 & $\mathrm{~F}$ & III & 60 & 38 & 7 & d \\
\hline 2 & M.P. & 54 & $\mathrm{~F}$ & III & 85 & 71 & 14 & a \\
\hline 3 & L.A.P. & 63 & $F$ & III & 65 & 53 & 7 & a \\
\hline 4 & G.M.O. & 28 & $M$ & IV & 55 & 44 & 7 & 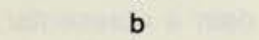 \\
\hline 5 & F.E.S. & 29 & $\mathrm{~F}$ & III & 70 & 45 & 8 & b \\
\hline 6 & M.M.V. & 48 & $F$ & III & 105 & 75 & 10 & b \\
\hline 7 & J.C.S. & 18 & $M$ & III & 65 & 45 & 7 & d \\
\hline 8 & B.D.S. & 25 & $M$ & III & 55 & 40 & 8 & c \\
\hline 9 & S.A.G.V. & 28 & $\mathrm{~F}$ & III & 70 & 55 & 7 & a \\
\hline 10 & J.L.A. & 30 & $M$ & III & 80 & 50 & 8 & a \\
\hline 11 & T.B.B. & 46 & $\mathrm{~F}$ & III & 145 & 140 & 8 & a \\
\hline 12 & V.E.S. & 27 & $M$ & III & 105 & 85 & 14 & a \\
\hline 13 & L.V.S. & 45 & $\mathrm{~F}$ & III & 90 & 80 & 7 & a \\
\hline 14 & A.A.S. & 18 & $\mathrm{~F}$ & III & 90 & 60 & 13 & c \\
\hline 15 & E.V.S. & 60 & $\mathrm{~F}$ & III & 115 & 84 & 12 & c \\
\hline 16 & M.A.T. & 47 & $\mathrm{~F}$ & III & 75 & 62 & 7 & a \\
\hline 17 & J.R.C. & 32 & M & III & 80 & 57 & 8 & a \\
\hline 18 & N.P.N. & 50 & $\mathrm{~F}$ & III & 70 & 55 & 7 & a \\
\hline 19 & M.F. & 51 & $M$ & IV & 180 & 135 & 8 & c \\
\hline 20 & A.A.V. & 37 & $\mathrm{~F}$ & IV & 130 & 95 & Óbito 1.0. & a \\
\hline 21 & M.N.P. & 43 & $\mathrm{~F}$ & III & 135 & 125 & 7 & a \\
\hline 22 & F.V. & 56 & $M$ & III & 130 & 94 & 7 & b \\
\hline 23 & W.A.X. & 16 & $M$ & III & 70 & 60 & 18 & b \\
\hline
\end{tabular}

$38,13 \pm 14,18$

$92,32 \pm 32,94 \quad 71,65 \pm 29,59 \quad 9,05 \pm 3,11$

Técnica cirúrgica: a - fixação do topo dos músculos papilares no anel posterior; b - fixação dos músclos papilares e cordas tendíneas no anel posterior; c - excisão parcial apenas da cúspide anterior com fixação de seus papilares e cordas tendíneas conservando-se os elementos valvares da cúspide posterior; $d$ - conservaçăo de todo o aparelho valvar.

TABELA 2

CARACTERISTICAS INDIVIDUAIS DOS PACIENTES DO GRUPO B IPLASTIA MITRAL POR AMPLIAÇÃO DA CÚSPIDE POSTERIOR)

\begin{tabular}{|c|c|c|c|c|c|c|c|}
\hline CASO & INICIAIS & IDADE (ANOS) & SEXO & GRAU FUNC. & TP (MIN.) & TAO (MIN.) & ALTA HOSPITALAR (DIA) \\
\hline 1 & J.P.S. & 29 & $\mathrm{~F}$ & III & 120 & 110 & 10 \\
\hline 2 & A.C.B. & 32 & $M$ & III & 130 & 118 & 12 \\
\hline 3 & M.M.P.M. & 44 & $\mathrm{~F}$ & III & 90 & 75 & 8 \\
\hline 4 & E.D.A. & 10 & $M$ & III & 95 & 90 & 7 \\
\hline 5 & E.M.M. & 38 & $F$ & III & 70 & 55 & 13 \\
\hline 6 & I.A.D. & 43 & $\mathrm{~F}$ & II & 115 & 100 & 8 \\
\hline 7 & M.A.C.F. & 26 & $\mathrm{~F}$ & III & 75 & 55 & 7 \\
\hline 8 & D.M. & 39 & $\mathrm{~F}$ & III & 125 & 105 & 8 \\
\hline 9 & W.A.X. & 16 & $M$ & III & 110 & 93 & 6 \\
\hline 10 & R.A.S. & 18 & $\mathbf{F}$ & III & 85 & 73 & 6 \\
\hline 11 & A.F.P. & 15 & $\mathrm{~F}$ & IV & 120 & 90 & 7 \\
\hline 12 & M.E.S.C. & 15 & $F$ & II & 90 & 75 & 7 \\
\hline 13 & A.P.V. & 49 & $\mathrm{~F}$ & IV & 185 & 175 & Obito 6: P.O. \\
\hline 14 & L.D.C. & 33 & $M$ & III & 120 & 105 & 6 \\
\hline 15 & R.A.D. & 13 & $\mathrm{~F}$ & III & 100 & 85 & 7 \\
\hline 16 & R.F.O. & 17 & $M$ & III & 80 & 65 & 6 \\
\hline & & $27,31 \pm 12,74$ & & & $106,88 \pm 28,16$ & $91,81 \pm 29,16$ & $7,38 \pm 2,87$ \\
\hline
\end{tabular}


ÉVORA, P. R. B.; RIBEIRO, P. J. F.; BRASIL, J. C. F.; OTAVIANO, A. G.; REIS, C. L.; BONGIOVANI, H. L.; BOMBONATO, R.; FEREZ, M. A.; MENARDI, A. C.; SGARBIERI, R. N. - Experiência com dois tipos de técnicas para o tratamento cirúrgico da insuficiência mitral: I. Prótese com preservação de elementos do sistema valvar. II. Plastia valvar com reconstrução e avanço da cúspide posterior. Rev. Bras. Cir. Cardiovasc., 3(1): 36-49, 1988.

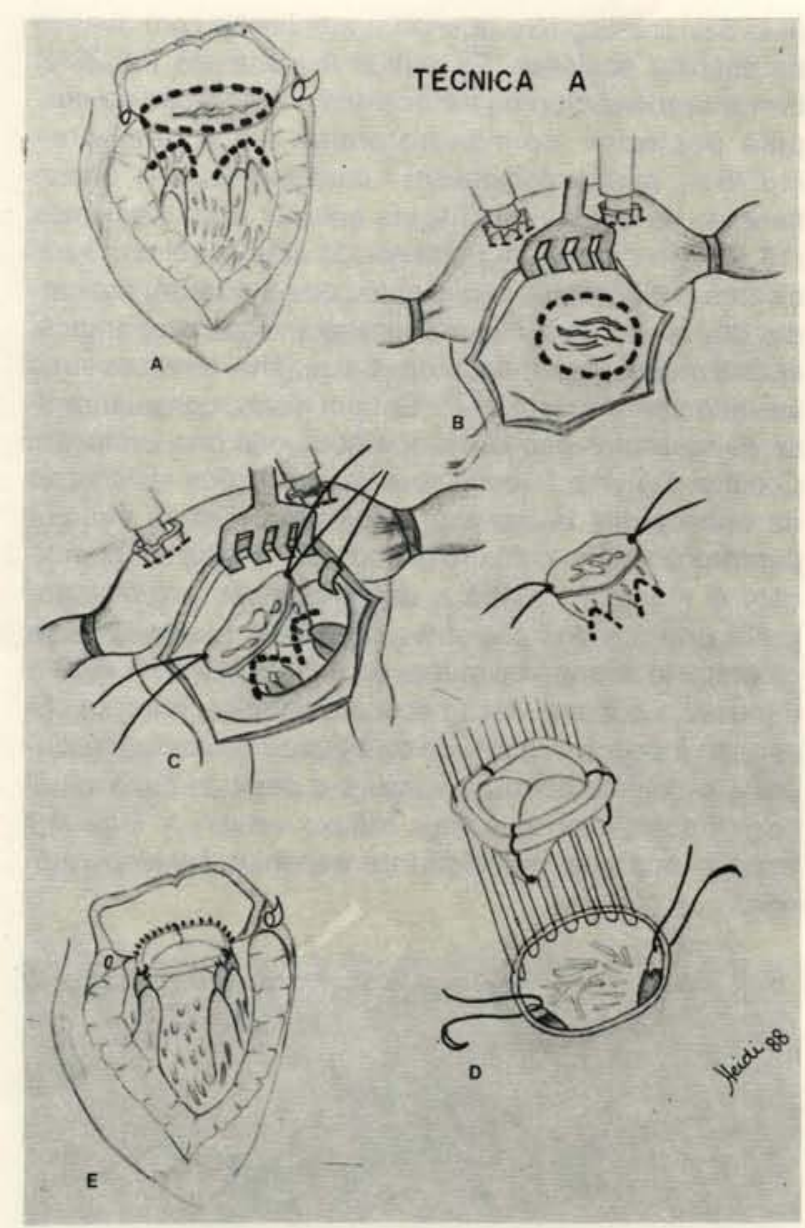

Fig. 1 - Prótese mitral com preservação de elementos do sistema subvalvar. Representação esquemática da Técnica a: fixação do topo dos músculos papilares no anel posterior.

anticoagulação, o que não ocorreu com os portadores de próteses biológicas. Todos faziam uso de $0,25 \mathrm{mg}$ por dia de digoxina na alta hospitalar. As características individuais de cada paciente encontram-se representadas na Tabela 1.

\section{Grupo B}

No período de julho de 1982 a dezembro de 1987 , realizaram-se 16 plastias mitrais com reconstrução e avanço da cúspide posterior, em 9 mulheres $(56,25 \%)$ e 7 homens $(43,75 \%)$ com idade de $26,86 \pm 13,60$ anos e pertencentes às classes funcionais II $(12,50 \%)$, III $(75,00 \%)$ e IV $(12,50 \%)$ da NYHA. A cirurgia constou da liberação da cúspide posterior do seu anel, deixando as cordas e os músculos papilares o mais livre possível da parede posterior do ventrículo esquerdo. A incisāo, que separa a cúspide estendeu-se sempre além das comissuras valvares. Um pequeno retalho de pericárdio bovino, a maior parte das vezes da forma semilunar, foi suturado entre $o$ anel posterior e a cúspide residual, promovendo um avanço deste em direção à cúspide oposta. A curvatura anterior do retalho é tal, que permite a coaptação com a cúspide anterior, corrigindo a insuficiência valvar (Figura 5). A interposição do pericárdio bovino foi realizada com sutura continua de polipropileno 4-0. Como procedimentos associados, realizaram-se: comissurotomias, papilarotomias, encurtamento de cordas da cúspide anterior e cerclagem posterior do anel mitral. Os pacientes não foram submetidos a anticoagulação e tiveram alta hospitalar fazendo uso de 0,25 $\mathrm{mg} / \mathrm{dia}$ de digoxina. As características individuais de cada paciente encontram-se representadas na Tabela 2.

\section{RESULTADOS}

No Grupo A, as técnicas de preservação do aparelho valvar foram utilizadas como se segue: 1) Técnica a - fixação do topo dos músculos papilares no anel posterior, em 13 pacientes $(56,50 \%)$; 2) Técnica $\mathbf{b}$ - fixação dos papilares e cordas tendíneas no anel posterior em

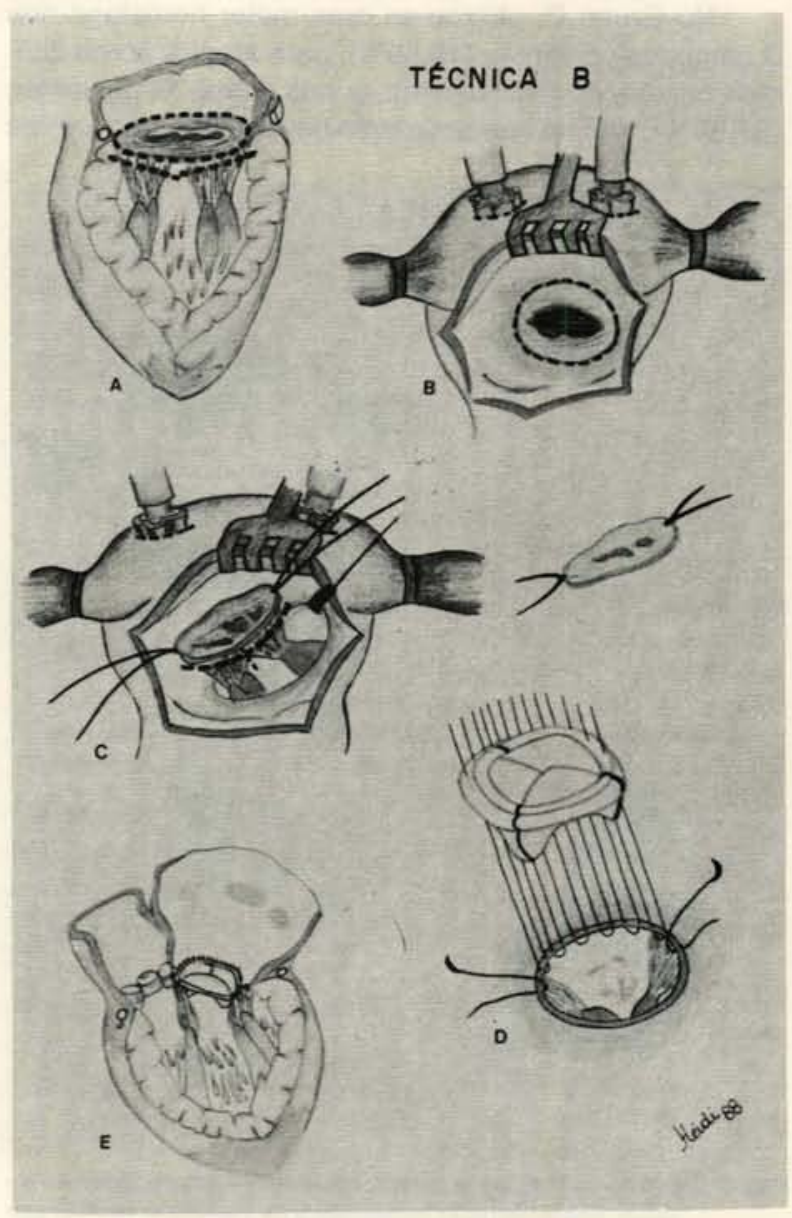

Fig. 2 - Prótese mitral com preservação de elementos do sistema subvalvar. Representação esquemática da Técnica b: fixação dos músculos papilares e cordas tendineas no anel posterior. 
ÉVORA, P. R. B.; RIBEIRO, P. J. F.; BRASIL, J. C. F.; OTAVIANO, A. G.; REIS, C. L.; BONGIOVANI, H. L.; BOMBONATO, R.; FEREZ, M. A.: MENARDI, A. C.; SGARBIERI, R. N. - Experiência com dois tipos de técnicas para o tratamento cirúrgico da insuficiência mitral: I. Prótese com preservação de elementos do sistema valvar. II. Plastia valvar com reconstrução e avanço da cúspide posterior. Rev. Bras. Cir. Cardiovasc., 3(1): 36-49, 1988.

4 pacientes $(17,40 \%)$; 3) Técnica c - excisão parcial apenas da cúspide anterior, com fixação de seus papilares e conservação das cordas tendíneas e papilares da cúspide posterior, em 4 pacientes $(17,40 \%)$; 4 ) Técnica d - conservação de todo o aparelho valvar em 2 pacientes $(8,70 \%)$. Utilizaram-s 3 próteses de disco $(13,00 \%)$ e 20 próteses biológicas $(87,00 \%)$ e, como procedimentos associados, realizaram-se: comissurotomia aórtica em 1 paciente, prótese aórtica em 3 pacientes, plástica tricúspide tipo De Vega e cerclagem de aneurisma apical do ventrículo esquerdo em 1 paciente. Ocorreu apenas 1 óbito intra-operatório $(4,35 \%)$, por baixo débito cardiaco. Todos os outros pacientes tiveram excelente evolução pós-operatória, nāo necessitando de suporte inotrópico com catecolaminas no pós-operatório imediato. No retorno de 30 dias, apresentavam-se na classe funcional I da NYHA e, como se mantinham nas mesmas boas condiçōes, passaram a nāo mais utilizar digoxina, após 3 meses da operaçāo. Na Figura 6, apresenta-se uma documentaçāo ecocardiográfica bidimensional de um dos pacientes submetidos ao implante de prótese mitral com fixação dos músculos papilares no anel posterior.

No Grupo B, utilizou-se dura-máter homóloga nos 2 primeiros pacientes $(15,50 \%)$, para ampliação da cúspide posterior da valva mitral, e, nos outros 14 pacientes $(87,50 \%)$, retalhos de pericárdio bovino. Em 7 pacientes

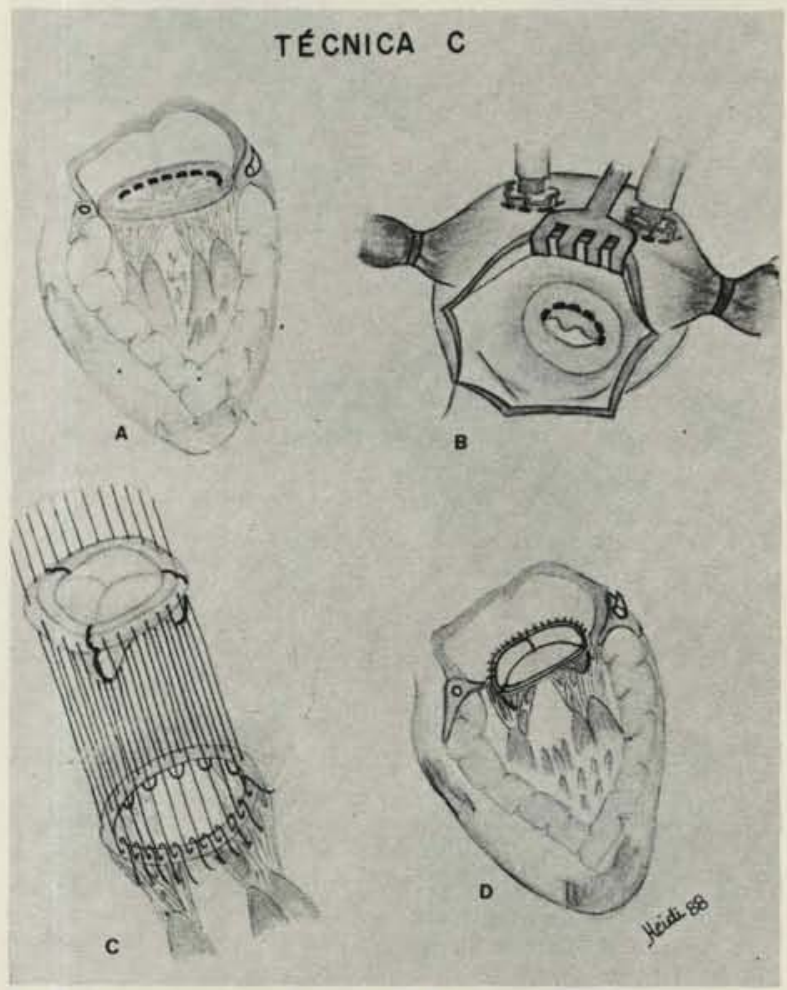

Fig. 3 - Prótese mitral com preservaçāo de elementos do sistema subvalvar. Representaçāo esquemática da Técnica c: excisâo parcial apenas da cúspide anterior com fixaçāo de seus papilares e cordas tendineas, conservando-se os elementos valvares da cúspide posterior.
(43,75\%), realizou-se apenas a ampliação com avanço da cúspide posterior. Os outros 9 pacientes $(56,25 \%)$ tiveram procedimentos associados à ampliação da cúspide posterior: comissurotomias em 3 pacientes $(18,75 \%)$, papilarotomias em 1 paciente $(6,24 \%)$, encurtamento de cordas da cúspide anterior em 2 pacientes $(17,50 \%)$ e cerclagem posterior do anel mitral em 3 pacientes $(18,75 \%)$. Dois pacientes que utilizaram pericárdio bovino de uma mesma amostra foram reoperados, após 3 meses, por endocardite bacteriana, tendo as suas valvas mitrais substituídas. Em um deles, conservaramse os músculos papilares, apresentando boa evolução. O outro paciente faleceu com complicações sistêmicas da endocardite bacteriana, após uma terceira cirurgia para troca valvar, com um período de 19 dias de internação. A Figura 7 mostra a documentação angiocardiográfica de um dos pacientes operados, observando-se o completo desaparecimento do refluxo valvar. A Figura 8 mostra a documentação ecocardiográfica, onde se observam a pouca mobilidade da cúspide posterior ampliada, a excelente abertura valvar e o perfil do fluxo mitral por Doppler, sem que haja refluxo valvar. A Figura 9 mostra uma documentáção de aspectos intra-operatórios.

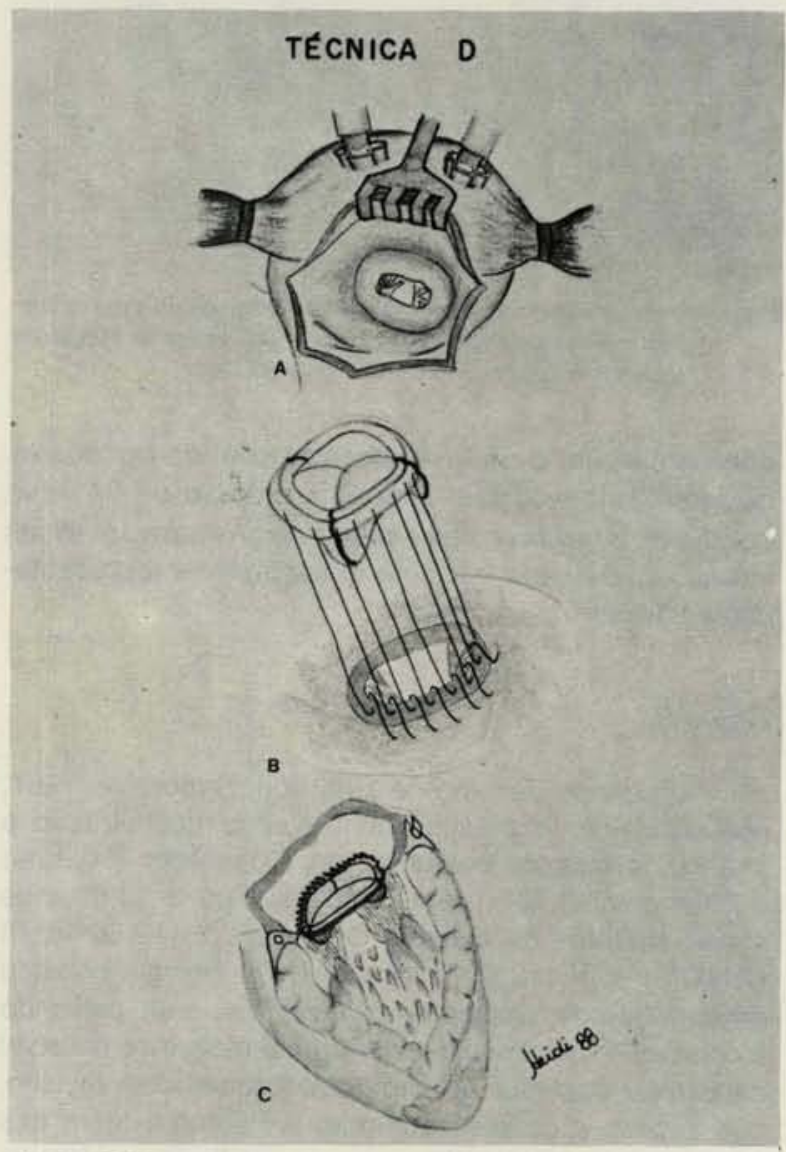

Fig. 4-Prótese mitral com preservação de elementos do sistema subvalvar. Representaçăo esquemática da Técnica d: conservação de todo o aparelho valvar. 
ÉVORA, P. R. B.; RIBEIRO, P. J. F.; BRASIL, J. C. F.; OTAVIANO, A. G.; REIS, C. L.; BONGIOVANI, H. L.; BOMBONATO. R.; FEREZ, M. A.; MENARDI, A. C.; SGARBIERI, R. N. - Experiência com dois tipos de técnicas para o tratamento cirúrgico da insuficiência mitral: I. Prótese com preservação de elementos do sistema valvar. II. Plastia valvar com reconstruçāo e avanço da cúspide posterior. Rev. Bras. Cir. Cardiovasc., 3(1): 36-49, 1988.

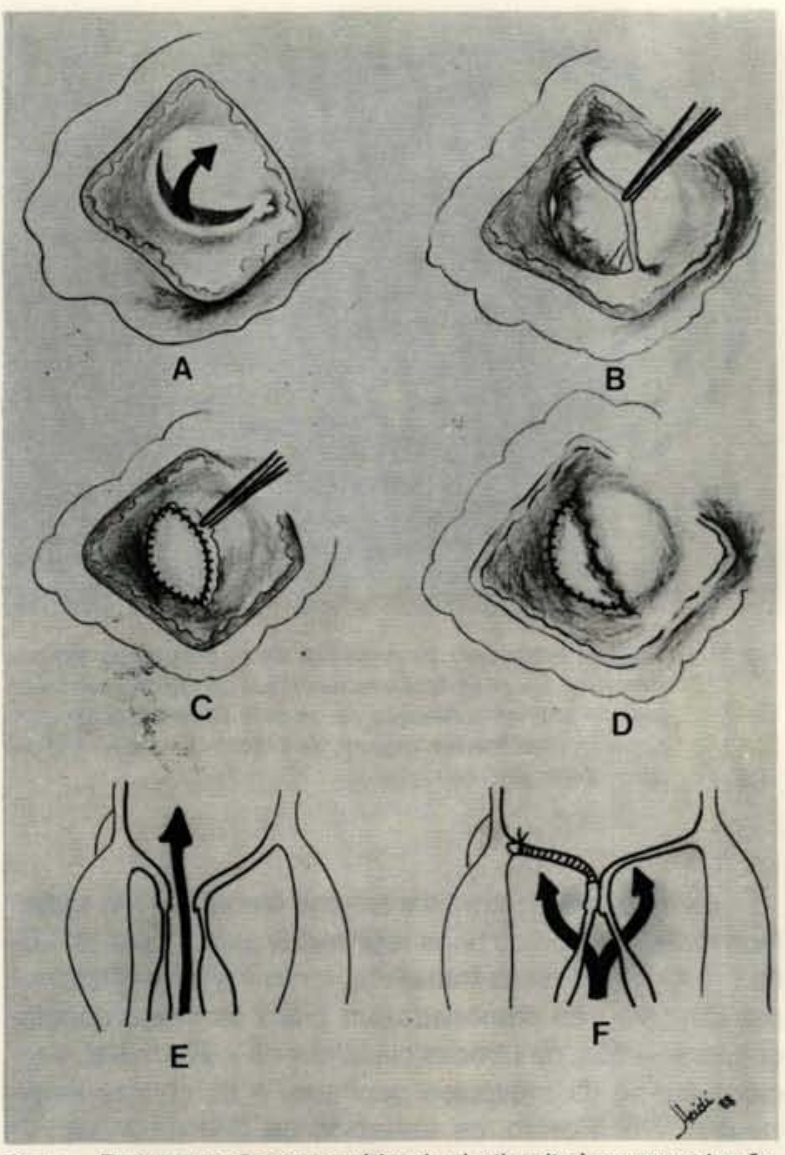

Fig. 5 - Representação esquemática da plastia mitral por reconstrução e avanço da cúspide posterior. A - valva mitral insuficiente; B - incisão da cúspide ao longo do anel valvar; C e D reconstrução e avanço da cúspide restabelecendo a competência valvar; E e F - representação esquemática em corte da técnica (copiado de SAUVAGE et alii. Surgery, 53(2): 213-221, 1963)

\section{DISCUSSÃO}

A contração máxima dos músculos papilares, ao final da sístole ventricular, participa do fechamento da valva mitral, além de aproximar a ponta do coração do plano das valvas aórtica e mitral. Com isto, há um encurtamento do eixo longitudinal, com aumento do eixo menor do ventrículo esquerdo. Isto permite que as fibras miocárdicas contraiam-se, adicionalmente, ocorrendo, em conseqüência, maior tensão, maior contração e, portanto, um maior aumento do volume sistólico ${ }^{44,45,53}$.

A base teórica para a preservação dos elementos do aparelho valvar, nas cirurgias para a correção do refluxo mitral, estabelecidas na introdução deste trabaIho, pode ter o seu embasamento nos seguintes tópicos: 1) é importante a continuidade entre a valva e a parede ventricular, na preservação da "geometria funcional" do ventrículo esquerdo; 2) ocorre menor morbi-mortalidade,
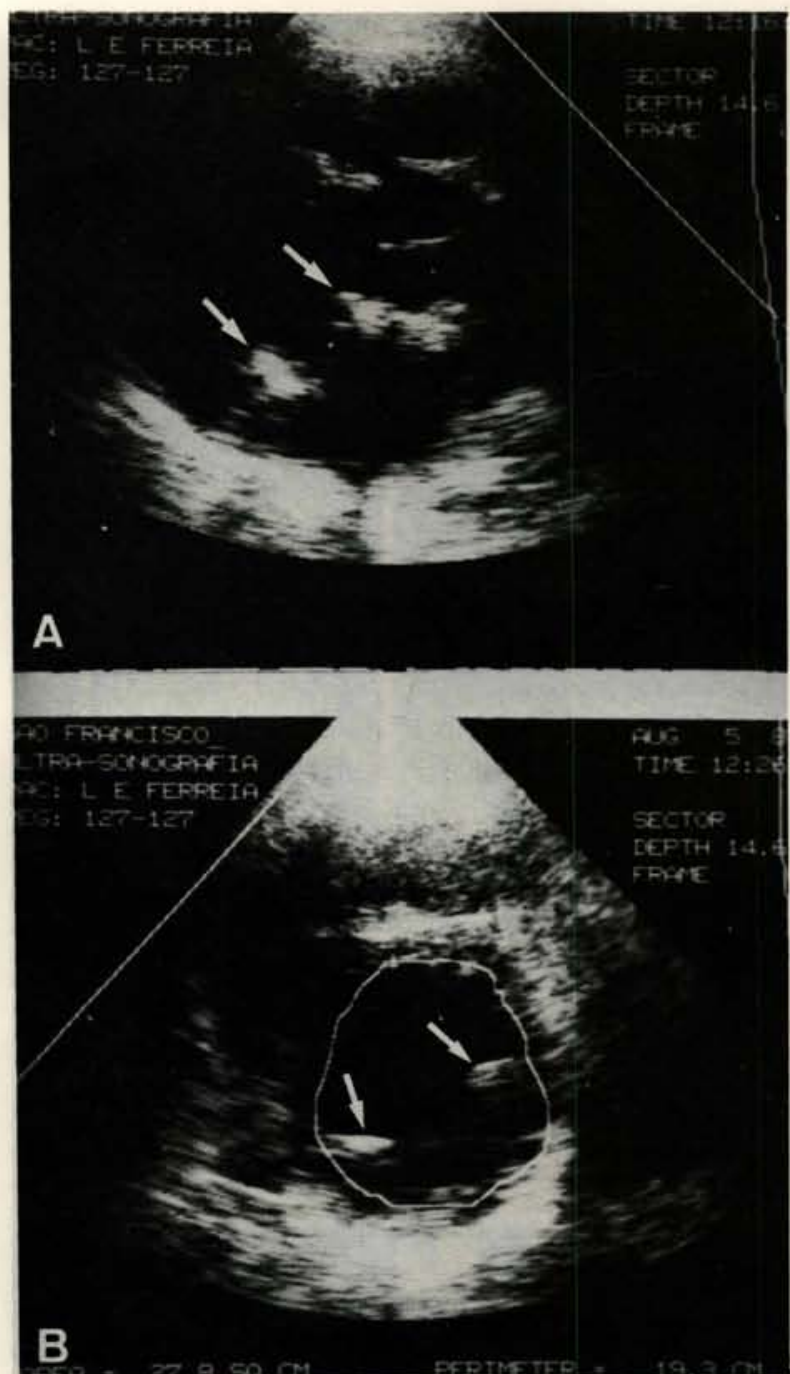

Fig. 6 - Documentaçāo ecocardiográfica bidimensional de um dos pacientes submetidos ao implante de prótese mitral com fixação dos músculos papilares no anel posterior. As setas indicam as imagens dos papilares.

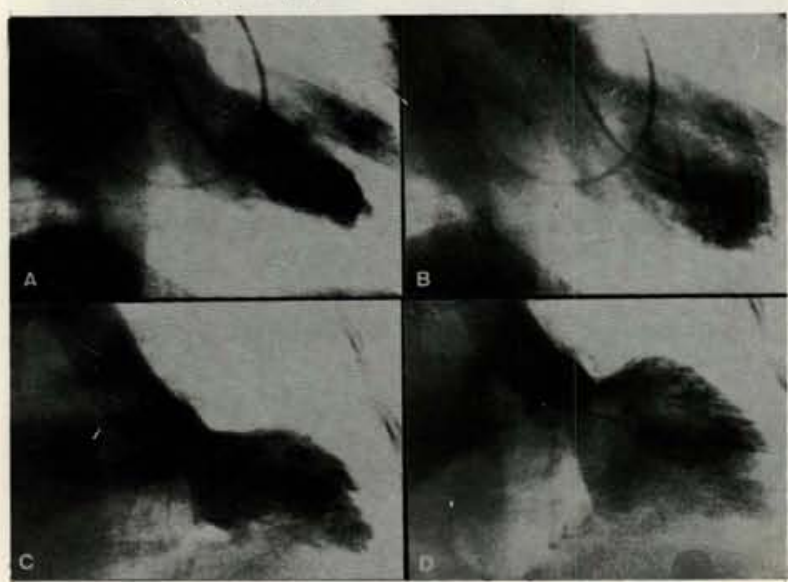

Fig. 7 - Documentaçâo angiocardiográfica de um dos pacientes operados com reconstrução e avanço da cúspide posterior. Observa-se o completo desaparecimento do refluxo valvar mitral. 
ÉVORA, P. R. B.; RIBEIRO, P. J. F.; BRASIL, J. C. F.; OTAVIANO, A. G.; REIS, C. L.; BONGIOVANI, H. L.; BOMBONATO, R.; FEREZ, M. A.; MENARDI, A. C.; SGARBIERI, R. N. - Experiência com dois tipos de técnicas para o tratamento cirúrgico da insuficiência mitral: I. Prótese com preserỵação de elementos do sistema valvar. II. Plastia valvar com reconstrução e avanço da cúspide posterior. Rev. Bras. Cir. Cardiovasc., 3(1): 36-49, 1988.

nos casos de valvoplastias, quando comparadas com as trocas valvares, ressaltando-se menor incidência de síndrome de baixo débito cardíaco;3) a melhora sintomática, após a substituição valvar, sem conservação de seus elementos, parece dever-se mais a um aumento do volume sistólico do que, propriamente, a uma real recuperaçāo da funçāo ventricular esquerda.
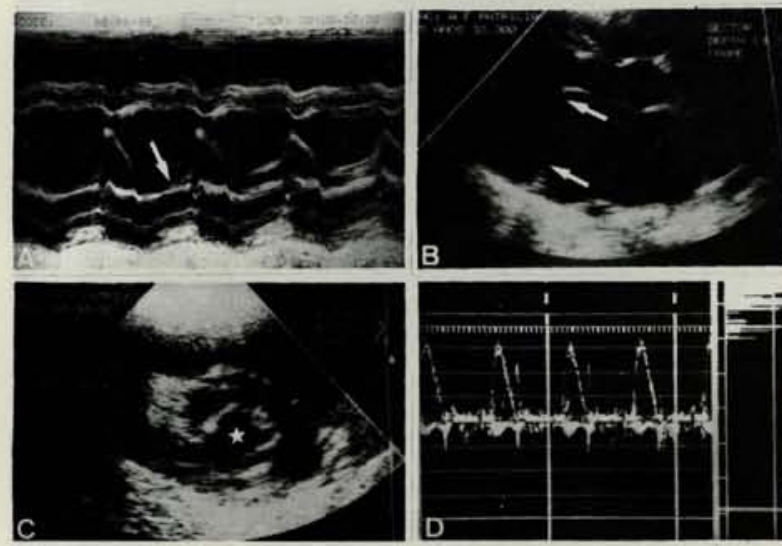

Fig. 8 - Documentaçâo ecocardiográfica de um dos pacientes operados com reconstruçăo e avanço da cúspide posterior. A - modo M: a seta indica a quase imobilidade da cúspide posterior reconstruida: B - ecocardiograma bidimensional: as setas indicam a boa abertura da valva mitral; $\mathrm{C}$ - ecocardiograma bidimensional: a marca indica a boa abertura valvar mitral; D Doppler mostrando a inexistência de refluxo valvar mitral.

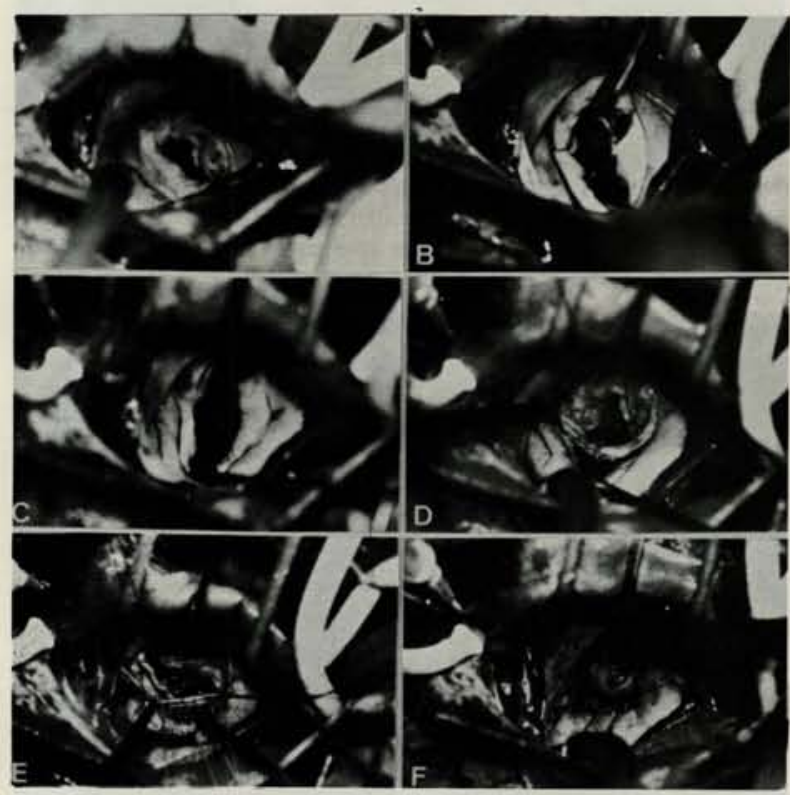

Fig. 9-Aspectos intra-operatórios da reconstruçâo com avanço da cúspide posterior da valva mitral. A - valva mitral mostrando dupla lesão; B - comissurotomia valvar; C - papilarotomia; $\mathrm{D}$ - desinserção da cúspide posterior do anel valvar; $\mathrm{E}-$ cerclagem do anel posterior; $F$ - reconstrução da cúspide posterior com pericárdio bovino.

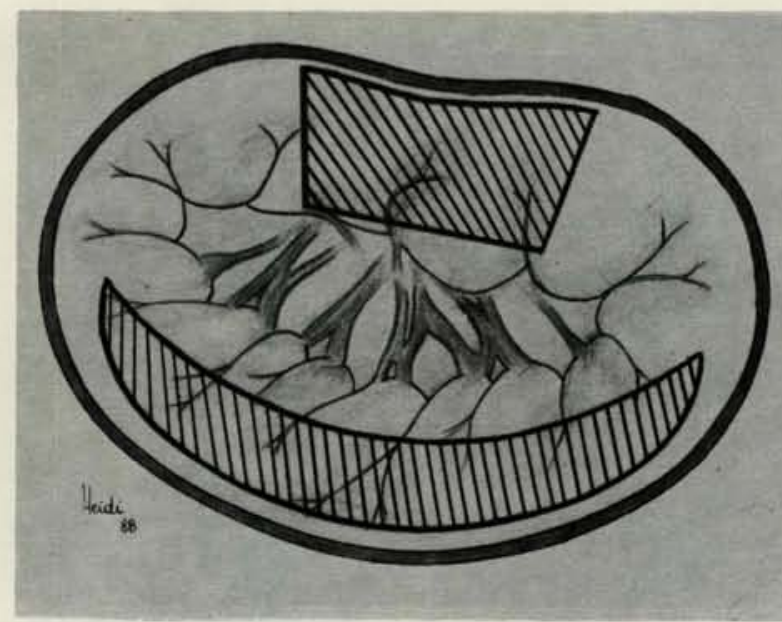

Fig. 10-Prótese mitral com conservaçāo de elementos do sistema subvalvar. Representação esquemática da excisāo parcial da cúspide anterior e reduçăo da cúspide posterior conservando-se as suas bordas (copiado de DAVID, T.E. Ann. Thorac. Surg., 41(6): 680-682, 1986)

Existem dados conflitantes, na literatura, em trabaIhos motivados pelos bons resultados obtidos por LILLE$\mathrm{HEI}^{31}$. Alguns desses trabalhos, tanto experimentais como clínicos, não demonstraram piora da função ventricular esquerda, nas trocas clássicas da valva mitral, seccionando-se os músculos papilares e as cordas tendíneas $^{4}, 36,40$. Porém, os trabalhos de DAVID et alii ${ }^{15-18}$ (Figura 10), HETZER et alii ${ }^{25}$ e MIKI et alii ${ }^{33}$ demonstraram, de forma bastante convincente, melhora da função ventricular esquerda, no que diz respeito aos volumes ventriculares e às pressões finais diastólicas do ventrículo esquerdo.

Um outro aspecto a ser considerado diz respeito ao anel mitral e aos músculos papilares: a fixação do anel por um elemento rígido poderia causar deterioraçāo da funçāo ventricular esquerda, o mesmo ocorrendo com a divisão dos músculos papilares e cordas tendíneas ${ }^{50}$. Durante a sístole, a área do anel valvar diminui de 20 a $50 \%$ por contração dos músculos bulbo-espiral e sinoespiral, que circundam a base do coração e se inserem no anel valvar ${ }^{9,19,38}$. A explicação da deterioração extrema da função ventricular, após a divisão das cordas tendíneas e músculos papilares, é incerta, mas é provável que a continuidade com o anel mitral tenha um importante papel na regulação da pré carga em diferentes partes do coração, para produzir máxima contração eíeti$\mathrm{va}^{36}$. Estes dados, que demonstram as particularidades da valva mitral e seus elementos na preservação da função ventricular esquerda, tornando-a única, nesse aspecto, e o fato de a morbidade e a mortalidade, nas trocas valvares mitrais, permanecerem altas, justificam todos os esforços de ampliação dos estudos na correção do refluxo valvar mitral. Talvez estes conceitos não tenham tanta importância, nas trocas valvares por esteno- 
ÉVORA, P. R. B.; RIBEIRO, P. J. F.; BRASIL, J. C. F.; OTAVIANO, A. G.; REIS, C. L.; BONGIOVANI, H. L.; BOMBONATO, R.; FEREZ, M. A.; MENARDI, A. C.; SGARBIERI, R. N. - Experiência com dois tipos de técnicas para o tratamento cirúrgico da insuficiência mitral: I. Prótese com preservaçăo de elementos do sistema valvar. II. Plastia valvar com reconstrução e avanço da cúspide posterior. Rev. Bras. Cir. Cardiovasc., 3(1): 36-49, 1988.

ses mitrais avançadas, onde existe um aparelho valvar rígido, fibrótico e nāo contrátil ${ }^{15}$. Nesses casos, é provável que a completa excisão da valva nativa e a sua substituição por protese não tragam alterações significativas da função ventricular.

A técnica de preservação do aparelho valvar, descrita originalmente por LILLEHEI ${ }^{31}$, é, ainda, a mais utilizada, principalmente após a sua "ressuscitação" pela escola canadense, ressaltando-se, mais uma vez, os trabalhos de DAVID et alii ${ }^{15-18}$. Por essa técnica, excisa-se, total ou parcialmente, a cúspide anterior, podendo permanecer tecidos redundantes capazes de interferir com a funçăo da prótese valvar, ou, ainda, facilitar o aparecimento de fenômenos trombo-embólicos, apesar do uso de anticoagulação. A solução proposta por Lillehei, nesses casos, consiste em uma sutura contínua do resíduo da cúspide anterior, "acolchoando-a", por assim dizer, e, posteriormente, procedendo-se ao implante da prótese. David e seus colaboradores aperfeiçoaram um detalhe técnico, para esses casos, pelo qual realizam uma parcial excisão da cúspide anterior e reduzem a cúspide posterior redundante, por meio de uma incisão semelhante à utilizada na ampliação da cúspide mitral, descrita por SAUVAGE \& WOOD ${ }^{46}$, só que, evidentemente, ao invés de interporem um retalho, ressuturam as bordas da incisão, reduzindo a cúspide posterior, segundo HETZER et alii ${ }^{25}$. Estes autores "reimplantam", por assim dizer, as cordas tendíneas no seu local de origem na cúspide anterior, ao contrário de MIKI et alii ${ }^{33}$, que fazem a fixação das cordas tendíneas anteriores no anel posterior, como nos 4 pacientes apresentados, no quais se conseguiu a preservação das cordas tendíneas. Nos casos operados nesta série, o problema do "acolchoamento" dos tecidos residuais após a excisão de cúspides foi resolvido passando-se os pontos separados do implante valvar, tipo "chuleio" e não em "U", como nas cirurgias clássicas de próteses valvares. $\mathrm{Na}$ maioria dos pacientes operados $(56,50 \%)$, procedeu-se à excisão de ambas as cúspides valvares extremamente comprometidas pelo processo reumático. As corda tendineas, nesses casos, inexistiam, havendo fusão do topo dos músculos papilares com a comissura valvar. Nesses casos, toma-se o cuidado, na ressecção das cúspides, de deixar o topo dos músculos papilares com a fibrose resultante da fusão das cordas tendíneas. Essa fibrose é cuidadosamente esculpida, para servir de apoio para o ponto que fixará o músculo papilar no anel posterior, próximo das comissuras. Esse cuidado também serve para evitar que os papilares fiquem excessivamente encurtados, o que também resultaria em mudança da "geometria" do ventrículo esquerdo, podendo interferir na sua função.

Restaria discutir os tipos de próteses a serem utilizadas, quando se preserva o aparelho, ou elementos do aparelho valvar. Nos trabalhos da década de 60 , a prótese utiliada foi a de Starr-Edwards, porém as próteses de bola devem oferecer maior risco de interferência, no seu funcionamento, por parte dos elementos valvares conservados. As próteses mais utilizadas, na atualidade, são as de baixo perfil, verificando-se que, na retomada da experiência com essa técnica, empregaram-se mais próteses biológicas pelo receio da interferência na função das próteses sintéticas. Este fato, se não impossivel, é bastante improvável, pois, posteriormente, seguiu-se à utilização de próteses metálicas, usadas em 3 pacientes $(13,00 \%)$, aqui documentados sem qualquer problema de disfunção protética. Deve-se ter em mente que, muitas vezes, a prótese selecionada será de um número menor do que a normalmente escolhida, quando se procede à clássica troca valvar. Este fato não traz, absolutamente, nenhum inconveniente, uma vez que as próteses com um número menor possuem fluxos mais do que suficientes, inclusive diminuindo a possibilidade do comprometimento do trato de saída do ventrículo esquerdo.

Sabe-se que a prática dos implantes valvares mitrais com preservação de seus elementos tem caminhado para um uso rotineiro, em diversos Serviços de cirurgia cardiaca, no Brasil, porém poucas são as divulgações nacionais sobre 0 assunto ${ }^{3,11,12,22,23}$.

A técnica da plastia valvar utilizada nos 16 pacientes do Grupo B foi denominada, por SAUVAGE et alii ${ }^{46 .}$ 47. ${ }^{48}$, de "avanço da cúspide" (leaflet advancement), que, em sua experiência, utilizou retalhos de pericárdio autógeno de forma oval, para ampliar, usualmente, a cúspide aórtica. Nos trabalhos originais, o autor define as seguintes indicaçōes anatômicas, para a utilização da técnica: 1) anel valvar normal ou pequeno; 2 ) flexibilidade razoável das cúspides valvares; 3 ) uma cúspide que, embora rígida, possa tornar-se flexível por desbridamento; 4) cordas tendíneas, as quais, embora encurtadas ou fundidas, possam ter, ainda, razoável flexibilidade residual, que também pode ser conseguida, além do desbridamento, por separação dos papilares, ou papilarotomias. $\mathrm{O}$ autor também define quais seriam as contra-indicações anatômicas para a técnica: 1) dilatação significativa do anel valvar; 2) cúspides muito espessadas ( $4 \mathrm{~mm}$ ou mais), mesmo com alguma flexibilidade; 3 ) calcificação intensa das cúspides, que não podem se tornar flexíveis por desbridamento; 4) cordas tendíneas alongadas, permitindo o prolapso valvar. $O$ detalhe mais importante para o sucesso da operação é uma adequada separação da cúspide a ser ampliada, do anel valvar. Usualmente, é necessário estender-se a incisão ligeiramente além de cada comissura, criando-se uma área a ser ocupada pelo retalho cerca de $25 \%$ maior que o orifício de regurgitação valvar. A face lisa do retalho deve ficar voltada para o átrio e a sua sutura deve ser contínua, porém com freqüentes interrupçōes.

Além do pericárdio autógeno, utilizado originalmente por Sauvage, outros materiais foram empegados na restauração da cúspide mitral: fascia-lata autógena ${ }^{24}$, pare- 
ÉVORA, P. R. B.; RIBEIRO, P. J. F.; BRASIL, J. C. F.; OTAVIANO, A. G.; REIS, C. L.; BONGIOVANI, H. L.; BOMBONATO. R.; FEREZ, M. A.; MENARDI, A. C.; SGARBIERI, R. N. - Experiência com dois tipos de técnicas para o tratamento cirúrgico da insuficiência mitral: I. Prótese com preservaçāo de elementos do sistema valvar. II. Plastia valvar com reconstrução e avanço da cúspide posterior. Rev. Bras. Cir. Cardiovasc., 3(1): 36-49, 1988.

de atrial livre, nos casos de retraçāo da cúspide aórtica', material sintético, como o Ivalon², a dura-máter (SADER*) e, atualmente, o pericárdio bovino ${ }^{40}$.

Na série de 16 pacientes apresentados neste trabaIho, utilizaram-se apenas ampliações com avanço da cúspide posterior, que tem sido a situação mais freqüente entre pacientes com refluxo valvar mitral. Ao contrário da descrição de Sauvage, onde a forma do retalho era oval, na presente experiência os retalhos têm mais a forma semilunar, com pequena curvatura na face côncava, que é suturada no anel valvar, sutura esta que se inicia e termina além das comissuras. Pelas observaçōes dos estudos ecocardiográficos pós-operatórios, onde se observou que a cúspide ampliada fica com baixa mobilidade, passou-se a recortar os retalhos um pouco redundantes, para facilidade de coaptação com a cúspide anterior.

Um outro dado importante diz respeito às contra-indicaçōes descritas por Sauvage, pois a presente experiência mostra que a única contra-indicação absoluta da técnica é a calcificação intensa das cúspides que não podem se tornar flexiveis pelo desbridamento. $O$ espessamento das ( $4 \mathrm{~mm}$, ou mais) passa a ser uma contra-indicação relativa, interessando mais à situação da cúspide anterior, que, muitas vezes, é conservada. A dilatação do anel valvar e o alongamento das cordas tendíneas deixam de ser contra-indicações, uma vez que, além de comissurotomias e papilarotomias, associaram-se ao avanço da cúspide a cerclagem posterior do anel mitral e o encurtamento de cordas. À medida em que a experiência do grupo aumentou, com as diversas técnicas modernas de plastias valvares, 0 avanço da cúspide posterior incorporou-se ao arsenal de recursos técnicos, sendo utilizada cada vez com mais freqüência, observando-se, inclusive, que metade dos pacientes foram operados no último ano. Esta, talvez, constitua-se na maior lição fornecida por esta série, uma vez que se sente, pela literatura, congressos e contatos com diversas equipes cirúrgicas, que a ampliação da cúspide valvar mitral é muito pouco lembrada. Assim é que uma vasta experiência com 83 plastias valvares mitrais, realizadas, até 1987, no InCor de São Paulo, apenas 1 caso foi submetido à ampliação da cúspide anterior ${ }^{39}$. Finalmente, podese questionar, pelo tempo de evolução dos pacientes operados, se haveria vantagens da técnica, em relação ao implante das próteses. Tudo leva a crer que sim; pelo menos no que diz respeito à anticoagulação, só utilizada em pacientes com grande aumento do átrio esquerdo e com fibrilação atrial. Além disto, pode-se atentar para a possibilidade de utilização da ampliação da cúspide anterior.

A série ainda é pequena e, embora tenham ocorrido 2 casos de endocardite, os resultados estimulam a continuar na utilização desta técnica de correção plástica do refluxo valvar mitral.

ÉVORA, P. R. B.; RIBEIRO, P. J. F.; BRASIL, J. C. F.; OTAVIANO, A. G.; REIS, C. L.; BONGIOVANI, H. L.; BOMBONATO, R.; FEREZ, M. A.; MENARDI, A. C.; SGARBIERI, R. N. - Experience with two techniques for valve replacement: I. Prosthesis with preservation of the valvar elements. II. Valvar repair with reconstruction and advancement of the posterior leaflet. Rev. Bras. Cir. Cardiovasc., 3(1): 36-49, 1988.

ABSTRACT: The continuity between mitral valve and the left ventricular wall through chordae tendinae and papillary muscles plays a role in left ventricular function. The morbity and mortality for mitral valve replacement remain much higher than other cardiac procedures such as aortic valve replacement, mitral valvuloplasty and coronary artery bypass grafts. These facts justify all possible studies related to the correction of mitral valve insufficiency. The present paper presents our experience with two techniques for correction of mitral valve insufficiency: valve replacement with preservation of the mitral apparatus components and valvuloplasty by the reconstruction and advancement leaflet. Our main concern was the surgical details and ventricular function studies were not performed. Various techniques to maintain continuity of the mitral valve annulus and the ventricular musculature, when valve replacements is mandatory, are presented. The importance of the reconstruction and advancement of the posterior leaflet, alone or associated with other repair techniques such as comissurotomy, annuloplasty and shortening of chordae tendinae, is emphasized.

DESCRIPTORS: mitral insufficiency, surgery; heart valves, surgery.

- SADER, A. A. - Comunicação pessoal, 1975. 
ÉVORA, P. R. B.; RIBEIRO, P. J. F.; BRASIL, J. C. F.; OTAVIANO, A. G.; REIS, C. L.; BONGIOVANI, H. L.; BOMBONATO. R.; FEREZ, M. A.; MENARDI, A. C.; SGARBIERI, R. N. - Experiência com dois tipos de técnicas para o tratamento cirúrgico da insuficiência mitral: I. Prótese com preservação de elementos do sistema valvar. II. Plastia valvar com reconstrução e avanço da cúspide posterior. Rev. Bras. Cir. Cardiovasc., 3(1): 36-49, 1988.

\section{REFERÊNCIAS BIBLIOGRÁFICAS}

1 BAILEY, C. P. - Autologous pericardium for mitral leaflet advancement. J. Thorac. Cardiovasc. Surg., 52(6): 872- , 1966.

2 BARNARD, C. N. \& SCHIRE, V. - Ivalon baffle for posterior leaflet replacement in the treatment of mitral insufficiency: a folow-up study. Surgery, 63(5): 727-730. 1968.

3 BATISTA, R. J. V.; DOBRIANSKYJ, A.; MOREIRA, R. R.; TIMI, J. R.; WESTPHAL, R.; LESSA, L. T.; OLIVEIRA, P. F. - A preservação do aparelho valvar mitral aumenta a expectativa de sobrevida e desempenho hemodinâmico na substituição mitral? Arq. Bras. Cardiol., 57(Supl. 1): 128, 1986. (Resumo).

4 BJÖRK, V. O.; BJÖRK, L.; MALERS, E. - Left ventricular function after resection of the papillary muscles in patients with total mitral valve replacement. J. Thorac. Cardiovasc. Surg., 48(4): 635-639, 1964.

5 BORKON, A. M.; McINTOSH, C. L.; VON RUEDEN, T. J.; MORROW, A. G. - Mitral valve replacement with Hancock bioprosthesis five to ten-year follow-up. Ann. Thorac. Surg., 32(2): 127-137, 1981.

6 CARPENTIER, A.; CHAUVAUD, S.; FABIANI, J. N.; DELOCHE, A.; RELLAND, J.; LESSANA, A.; D'ALLAINES, C.; BLONDEAU, P.; PIWNICA, A.; DUBOST, C. Reconstructive surgery of mitral valve incompetence: ten-year appraisal. J. Thorac. Cardiovasc. Surg., 79(3): 338-348, 1980.

7 CARPENTIER, A.; RELLAND, J.; DELOCHE, A.; FABIANI, J. N.; D'ALLAINES, C.; BLONDEAU, P.; PIWNICA, A.; CHAUVAUD, S.; DUBOST, C. - Conservative management of the prolapsed mitral valve. Ann. Thorac. Surg., 26(3): 294-302, 1978.

8 C. A. S. S. Coronary Artery Surgery Study - A randomized trial of coronary artery bypass surgery. Circulation, 68(5): 951-850, 1983.

9 CHIECHI, M.; LEES, W. M.; THOMPSON, R. - Functional anatomy of the normal mitral valve. J. Thorac. Surg., 32(3): 378-398, 1956.

10 CHRISTAKIS, G. T.; KORMOS, R. L.; WEISEL, R. D.; FREMES, S. E.; TONG, C. P.; HERST, J. A.; SCHWARTZ, L.; MICKLEBOROUGH, L. L.; SCULLY, H. E.; GOLDMAN, B. S.; BAIRD, R. J. - Morbidity and mortality in mitral valve surgery. Circulation, $72(3 \mathrm{Pt}$, 2): $120-128,1985$.

11 CIVIDANES, G. V. L.; FIORELLI, A. I.; TEÓFILO Jr., S.; KOPEL, L.; SILVA, E. E. R.; CIONGOLI Jr., S. M.; NETO, L. F.; CIONGOLI, W.; PUIG, L. B. - Preservação funcional dos músculos papilares na substituiçāo da valva mitral. Arq. Bras. Cardiol., 55(Supl. 1): 147. 1985. (Resumo).
12 CIVIDANES, G. V. L.; PUIG, L. B.; CIONGOLI, W. I.; TEOFILO Jr. S.; DONTOS, A. C.; SALLES FILHO, M. M. MELO, T. C. G. P.; OLIANI, J.; GONELLI, C. A.; SILVA E. E. R.; KOPEL, L. - Nossa experiência em substituição da valva mitral com preservação e fixação dos músculos papilares. Arq. Bras. Cardiol., 57(Supl. 1): 165, 1987. (Resumo).

13 COHN, L. H.; ALLRED, E. N.; DiSESA, V. J.; SAWTELLE, K. B. A.; SHEMIN, R. J.; COLLINS Jr., J. J. - Early and late risk of aortic valve replacement: a 12 year concomitant comparison of the porcine bioprosthetic and tilting disc prosthetic aortic valves. J. Thorac. Cardiovasc. Surg., 88(5): 695-704, 1984.

14 CZER, L. S. C.; GRAY, R. J.; De ROBERTIS, M. A.; BATEMAN, T. M.; STEWART, M. E.; CHAUX, A.; MATLOFF, J. M. - Mitral valve replacement: impact of coronary artery disease and determinants of prognosis after revascularization. Circulation, $\mathbf{7 0}(3 \mathrm{Pt} .2)$ 198-207, 1984.

15 DAVID, T. E. - Mitral valve replacement with preservation of chordae tendinae: rationale and technical considerations. Ann. Thorac. Surg., 41(6): 680-682, 1986.

16 DAVID, T. E.; BURNS, R. J.; BACCHUS, C. M.; DRUCK M. N. - Mitral valve replacement for mitral regurgitation with and without preservation of chordae tendinae. J. Thorac. Cardiovasc. Surg., 88(5): 718-725, 1984.

17 DAVID, T. E.; STRAUSS, H. D.; MESHER, E.; ANDERSON, M. J.; MacDONALD, J. L.; BUDA, A. J. - Is it important to preserve the chordae tendiane and papillary muscles during mitral valve replacement? Can. J. Surg., 24(2): 236-247, 1981.

18 DAVID, T. E.; UDEN, D. E.; STRAUSS, H. D. - The importance of the mitral apparatus in left ventricular function after correction of mitral regurgitation. Circulation, 68(Supl. 2): 76-82, 1983.

19 DAVIS, P. K. B. \& KINMONTH, J. B. - The movements of the annulus of the mitral valve. J. Cardiovasc Surg., (Torino), 4(4): 427-431, 1963.

20 DOCES, J. \& KENNEDY, J. W. - Quantitative assessment of left ventricular function following successful mitral valve surgery. Am. J. Cardiol, 35: 132, 1975. (Resumo).

21 DURAN, C. G.; POMAR, J. L.; REVUELTA, J. M.; GALLO, I.; POVEDA, J.; OCHOTECO, A.; UBAGO, J. L. Conservative operation for mitral insufficiency critical analisys supported by postoperative hemodynamic in 72 patients. J. Thorac. Cardiovasc. Surg., 79(3): $326-337,1980$

22 ÉVORA, P. R. B.; RIBEIRO, P. J. F.; BONGIOVANI, H L.; BRASIL, J. C. F.; ARÉVALO, J. R. S. - Trocas valvares mitrais com preservação dos músculos papilares. Congresso Paulista de Cardiologia. $8^{\circ}$. Sociedade de Cardiologia do Estado de São Paulo. São José do Rio Preto, SP, 1987. p. 9. (Resumos). 
ÉVORA, P. R. B.; RIBEIRO, P. J. F.; BRASIL, J. C. F.; OTAVIANO, A. G.; REIS, C. L.; BONGIOVANI, H. L.; BOMBONATO R.; FEREZ, M. A.; MENARDI, A. C.; SGARBIERI, R. N. - Experiência com dois tipos de técnicas para o tratamento cirúrgico da insuficiência mitral: I. Prótese com preservação de elementos do sistema valvar. II. Plastia valvar com reconstrução e avanço da cúspide posterior. Rev. Bras. Cir. Cardiovasc., 3(1): 36-49, 1988

LEPLEY, E. J.; FLEMMA, R. J.; MULLEN, D. C.; MOTL, M.; ANDERSON, A. J.; WEINRAUCH, E. - Longterm follow-up of Björk-Shiley prosthetic valve used in mitral position. Ann. Thorac Surg., 30(2): 164-172, 1980.

31 LILLEHEI, C. W.; LEVY, M. J.; BONNABEAU, R. C. Mitral valve replacement with preservation of papillary muscles and chordae tendinae. J. Thorac. Surg., 47(4): 532-543, 1964

LITWAK, R. S.; SILVAY, J.; GADBOYS, H. L.; LUKBAN, S. B.; SAKURAI, H.; CASTRO-BLANCO, J. - Factors associated with operative risk in mitral valve replacement. Am. J. Cardiol., 23(3): 335-348, 1969

33 MIKI, S.; KASUHARA, K.; UEDA, Y.; KOMEDA, M.; OHKITA, Y.; TAHATA, T. - Mitral valve replacement with preservation of chordae tendinae and papillary muscles. Ann. Thorac. Surg., 45(1): 28-34, 1987.

34 MILER Jr., D. W.; JOHNSON, D. D.; IVEY, T. D. - Does preservation of the posterior chordae tendinae enhance survival during mitral valve replacement? Ann. Thorac. Surg., 28(1): 22-27, 1979.
35 MORROW A G. OLDHAM, H.N. ELKINS, R C BRAUN WALD, E. - Prosthetic replacement of the mitral valve preoperative and postoperative clinical and hemodynamic assessments in 100 patients. Circulation. 35(3): 962-979, 1967.

36 MORTON, M. T.; BOHNSTED, S. W.; PANTELY, G. A. RAHIMTOOLA, S. - Effect of successful mitral valve replacement on left ventricular function. Circulation. 62(4 Pt. 2): 208, 1980. (Resumo).

37 NAJAFI, H.; DYE, W. S.; JAVID, H.; HUNTER, J. A.; OSTERMILLER Jr., W. E.; JULIAN, O. C. - Mitral valve replacement: review of sevem years' experience. Am. J. Cardiol., 24(3): 386-392, 1969.

38 ORMISTON, J. A.; SHAH, P. M.; TEI, C.: WONG, M. Size and motion of the mitral valve annulus in man a two-dimensional echocardiographic method and findings in normal subjects. Circulation, 64(1): 113-120 1981.

39 POMERANTZEFF, P. M. A.; STOLF, N. A. G.; AMATO, M.; MORETTI, M.; GRIMBERG, M.; MORAES, A. V. CAMARANO, G.; AULER Jr., J. O. C.; VERGINELLI, G.; JATENE, A. D. - Plástica de valva mitral: experiência do InCor. Arq. Bras. Cardiol., 59(Supl. 1) 161, 1987. (Resumo).

40 RASTELLI, G. C.; TSAKIRIS, A. G.; FRYE, R. L.; KIRKLIN J. W. - Exercise tolerance and hemodynamic studies after replacement of canine mitral valve with and without preservation of chordae tendinae. Circulation, 35(Supl. 1): 34-41, 1967.

41 REED, G. E. - Repair of mitral regurgitation: an 11 year experience. Am. J. Cardiol., 31(4): 494-496, 1973.

42 REED, G. E.; POOLEY, R. W.; MOGGRO, R. A. - Durability of measured mitral annuloplasty: seventeen year study. J. Thorac. Cardiovasc. Surg., 79(3): 321-325, 1980.

43 RIBEIRO, P. J. F.; ÉVORA, P. R. B.; ARÉVALO, J. R. G.; BRASIL, J. C. F.; BOMBONATO, R.; OTAVIANO, A. G. - Plastia valvar mitral por avanço do folheto posterior com pericárdio bovino. Congresso Paulista de Cardiologia. 8. Sociedade de Cardiologia do Estado de São Paulo. São José do Rio Preto, SP, 1987. p. 10. (Resumos).

44 RUSHMER, R. F. - Initial phase of ventricular systole: asynchronous contraction. Am. J. Physiol., 184(1): 188-194, 1956.

45 RUSHMER, R. F.; FINALASYON, B. L.; NASH, A. A. Movements of the mitral valve. Circ. Res., 4(3) 337-342, 1956.

46 SAUVAGE, L. R. \& WOOD, S. J. - Technique for correction of mitral insufficiency by leaflet advancement. J. Thorac. Cardiovasc. Surg., 51(5): 649-655, 1966. 
ÉVORA, P. R. B.; RIBEIRO, P. J. F.; BRASIL, J. C. F.; OTAVIANO, A. G.; REIS, C. L.; BONGIOVANI, H. L.; BOMBONATO R.; FEREZ, M. A.; MENARDI, A. C.; SGARBIERI, R. N. - Experiência com dois tipos de técnicas para o tratamento cirúrgico da insuficiência mitral: I. Prótese com preservação de elementos do sistema valvar. II. Plastia valvar com reconstrução e avanço da cúspide posterior. Rev. Bras. Cir. Cardiovasc., 3(1): 36-49, 1988.

47 SAUVAGE, L. R.; WOOD, S. J.; BERGER, K. E.; CAMP. BELL, A. A. - Autologous pericardium for mitral leaflet advancement. J. Thorac. Cardiovasc. Surg., 52(6): 849-854, 1966.

48 SAUVAGE, L. R.; WOOD, S. J.; BILL Jr., A. H.; LOGAN, G. A.; DEANE, P. G. - Pericardial autografts in clinical cardiac surgery. Surgery, 53(2): 213-221, 1963.

49 SELZER, A.; KELLY Jr., J. J.; KERTH, W. I.; GERBODE, F. - Immediate and long range results of valvuloplasty for mitral regurgitation due to ruptured chordae tendinae. Circulation, 45(Supl. 1): 52-56, 1972.

50 SPENCE, P. A.; PENISTON, C. M.; DAVID, T. E.; MIHIC, N.; JABR, K. A.; NARINI, P.; SALERNO, T. A. - Toward a better understanding of the etiology of left ventricular dysfunction after mitral valve replacement. Ann. Thorac. Surg., 41(4): 363-371, 1986.

51 STARR, A.; HERR, R. H.; WOOD, J. A. - Mitral replacement: review of six years experience. J. Thorac. Cardiovasc. Surg., 54(3): 333-358, 1967.

52 STEWART, S. \& DeWEESE, J. A. - The determinants of survival following reoperation on prosthetic cardiac valves. Ann. Thorac. Surg., 25(6): 555-557, 1978.

53 WIGGERS, C. S. \& KATZ, L. M. - Contour of the ventricular volume curves under different conditions. Am. J. Physiol., 58(4): 439-475, 1922.

54 YACOUB, M.; HALIM, M.; RADLEY-SMITH, R.; MCKAY, R.; NIJUELD, A.; TOWERS, M. - Surgical treatment of mitral regurgitation caused by floppy valves: repair versus replacement. Circulation, 64(Supl. 2): 210-216, 1981.

AGRADECIMENTOS: Aos Drs. Antônio Luis Secches e Luiz Antônio Pechiori Finzi, pela documentação angiocardiográfica. Ao Dr. Jorge Renê Garcia Arévalo, pela documentação ecocardiográfica. À Sra Rosa Pereira Brites Salles e ao Sr. Carlos de Araújo Arantes, pela documentação fotográfica. À Dra Heidi C. Maldonado, pela documentação artística. À Srta Roswita G. Borges Ribeiro, pelo serviço datilografado. Ao Dr. João José Carneiro, pelo auxílio na revisão bibliográfica.

\section{Discussão}

\section{DR. GERALDO MARTINS RAMALHO Rio de Janeiro, RJ}

Quero agradecer à Comissão Organizadora, a indicação de meu nome para comentar este trabalho. Aos autores, elogiar a importância e a qualidade do trabalho apresentado. Lellehei e colaboradores, em 1964, propuseram a preservação do folheto posterior, para diminuir a incidência de rotura do ventrículo esquerdo na substituição da valva mitral. Observaram, também, redução da mortalidade operatória e menor incidência de síndrome de baixo débito, em pacientes portadores de insuficiência mitral crônica. Mais recentemente, T. E. David e colaboradores avaliaram o desempenho da função ventricular antes e após a operaçāo, em pacientes submetidos a procedimentos da valva mitral, para correção da insuficiência crônica, usando 3 técnicas distintas: substituição da valva mitral convencional com retirada da valva nativa; substituição da valva mitral com preservação do folheto posterior e valvoplastia. Observamos, também, como, em estudos anteriores publicados por G. Schuler e A. D. Johnson, que a retirada da valva mitral e sua substituição por uma prótese resultaram numa significante diminuição da fração de ejeção do ventrículo esquerdo, no pós-operatório. Por outro lado, a fração de ejeção foi mantida no pós-operatório, em ambos os grupos tratados com métodos que conservaram as cordas tendíneas. Hansen, em 1986, demonstrou a importância do aparelho mitral no desempenho sistólico do ventrículo esquerdo, em experimentos em cães. Os autores mostram que, na série operada de 23 casos, apena 3 pacientes portadores de cardiomegalia importante e fibrilação atrial fazem uso de digital. Gostaria de comentar este aspecto, sugerindo aos autores, além da avaliação clínica, fazer investigação em bases fisiológicas, analisando a função ventricular através da ecocardiografia e da fração de ejeção do ventriculo esquerdo - métodos que podem fornecer parâmetros essenciais à análise da função ventricular. Chamaria, também, a atenção dos métodos de proteção do miocárdio, como de grande importância na preservação da função ventricular. Empregamos, em nossos casos operados, hipotermia a $30^{\circ} \mathrm{C}$, mantendo a aorta desclampeada. Raramente usamos cardioplegia. Consideramos ser importante a preservação do folheto posterior, para evitar a rotura do ventrículo esquerdo. Em nossa experiência global, antes de adotar esta conduta, tivemos 3 casos de rotura do ventrículo esquerdo, (slide) complicação grave, quase sempre de solução difícil e só solucionada quando diagnosticada durante $O$ ato cirúrgico. É nossa conduta atual conservar o folheto posterior nas substituiçōes da valva mitral na insuficiência mitral crônica. Em alguns casos, temos tido problemas com relação ao funcionamento das próteses metálicas, sendo necessário ressecar excesso de tecido, após sua colocação. Perguntaria se este fato ocorreu na série apresentada e como foi corrigido. Concordamos com os autores, com relaçāo às tentativas de plastia da valva mitral nativa. Temos usado a técnica proposta por Carpentier. Não temos experiência com a técnica apresentada. Acreditamos ser importante a continuidade no uso do método empregado e temos opiniâo de que só a experiência adquirida através do aprendizado permanente e contínuo é que levará a bons resultados. Obrigado. 
ÉVORA, P. R. B.; RIBEIRO, P. J. F.; BRASIL, J. C. F.; OTAVIANO, A. G.; REIS, C. L;; BONGIOVANI, H. L.; BOMBONATO, R.; FEREZ, M. A.; MENARDI, A. C.; SGARBIERI, R. N. - Experiência com dois tipos de técnicas para o tratamento cirúrgico da insuficiência mitral: I. Prótese com preservação de elementos do sistema valvar. II. Plastia valvar com reconstrução e avanço da cúspide posterior. Rev. Bras. Cir. Cardiovasc., 3(1): 36-49, 1988.

\section{DR. SÉRGIO DA SILVA CAMINHA}

\section{Rio de Janeiro, RJ}

Inicialmente, gostariamos de agradecer à Comissão Organizadora e à Sociedade Brasileira de Cirurgia Cardiovascular, pelo honroso convite para comentar este trabalho. Apesar dos avanços em próteses valvulares, proteção miocárdica, monitorização, nas últimas duas décadas, a mortalidade pós troca mitral permanece elevada, quando comparada a outros tipos de operaçōes, em cirurgia cardiaca, tais como as de revascularização. Entre as possiveis causas para isto, estão o tratamento clínico prolongado com indicação cirúrgica tardia, comprometimento miocárdico secundário à doença básica (febre reumática, cardiopatia isquêmica, etc.) e disfunção ventricular por perda de continuidade funcional entre 0 anel mitral e a parede ventricular, causada pela ressecção de músculos papilares e cordoalha. Lillehei, em 1964 , observou melhora da função ventricular com a preservação dos músculos papilares e cordas tendíneas. A preservação total dos papilares em troca mecânica e do folheto e aparelho subvalvar posterior, no todo ou em parte, em troca biológica tem sido nossa política, com a finalidade de prevenir rotura ventricular posterior e melhorar a função cardiaca. As técnicas descritas pelo grupo de Ribeirão Preto preservam a continuidade principal entre $o$ anel da prótese e a parede ventricular, pela reconstituiçāo de uma anatomia próxima à natural. Os resultados clínicos iniciais, para os 2 grupos de pacientes, nesta série, são excelentes, tendo em vista as classes III e IV da NYHA, pré-operatórias. Gostariamos de perguntar ao autor: 1:) Qual o grau de disfunção ventricular e de hipertensāo pulmonar pré-operatória dos pacientes e o método que pretende utilizar para quantificar e comparar a função ventricular, no pós-operatório tardio? 2:) Qual o percentual de pacientes de troca mitral, na sua Instituiçẫo, nos quais as técnicas descritas foram aplicadas? Parabenizamos o autor e seus colaboradores, pelo excelente trabalho, que se constitui numa importante contribuição para a cirurgia de valva mitral, em nosso meio.

\section{DR. JOÃO JOSÉ CARNEIRO Ribeiräo Preto, SP}

Como membro da Disciplina de Cirurgia Torácica e Cardiovascular da Faculdade de Medicina de Ribeirão Preto, mencionada pelo Dr. Paulo Évora, não poderia deixar de comentar a técnica divulgada por Sauvage, para correção da insuficiência mitral, pois ela tem sido empregada, em nosso Serviço, desde 1976, quando o Prof. Albert Sader operou o primeiro paciente. Em 1982, tínhamos 9 pacientes operados, usando dura-máter homóloga, alguns, e pericárdio autólogo, em outros, sempre com ótimos resultados imediatos. Desde então, não mais a abandonamos. Todos os pacientes se apresentam, no pós-operatório, em melhor grau funcional e, no exem- plo mostrado, a redução da área cardiaca é fantástica, após 3 meses de evolução (de grau IV para normal). Entretanto, corrigindo a lesāo mitral, nāo terminamos com a doença reumatismal e, a cada recidiva sua, o paciente estará sujeito a perder sua valva. Foi o que aconteceu com nosso primeiro paciente, que, 8 anos após, foi reoperado por recidiva da lesão mitral. A valva estava praticamente destruída pelo processo patológico, comprovado histologicamente, estar em atividade. Outras 2 pacientes foram reoperadas no 10 : e no $12^{\circ}$ mês de evolução pós-operatória, pela mesma causa. Isto não invalida a técnica; apenas chama a atenção para a necessidade de um seguimento muito adequado destes pacientes, a fim de que os novos surtos da doença fiquem sob controle rigoroso. Julgo importante os princípios ditados pelo Prof. Carpentier, em seus trabalhos de recuperação plástica da mitral, principalmente os referentes ao melhor momento cirúrgico. É necessário que convençamos nossos cardiologistas clínicos de que somos capazes de recuperar, cada vez mais, um número de valvas, sem a necessidade de substitui-las, mas que, para que isto aconteça, os pacientes precisam chegar mais cedo às nossas mãos. Os resultados ainda incertos e, por vezes, desastrosos das substituiçōes valvares vêm aumentar o valor do trabalho ora apresentado pela equipe do Hospital do Coraçāo de Ribeirão Preto. Por este valor e pela qualidade da apresentação, nossos cumprimentos e o estímulo para que continuem preservando as valvas, sempre que possivel.

\section{DR. ÉVORA \\ (Encerrando)}

Aos Drs. Geraldo Ramalho e Sérgio Caminha, este nosso trabalho teve, como objetivo principal, a apresentação de técnicas cirúrgicas relacionadas com o tratamento da insuficiência mitral. Não se realizaram estudos da função ventricular esquerda, tanto no pré como no pós-operatório. Aceitamos e agradecemos as sugestōes para a realização desses estudos, que poderão ser feitos ambulatorialmente, por meio de métodos não invasivos, principalmente pela ecodopplercardiografia. Ao Dr. Geraldo Ramalho: achamos interessante a relação de não preservação do folheto posterior com rotura do ventrículo esquerdo. Em nossa casuística, tal situação não ocorreu, mas trata-se de um fato a mais para a justificativa da preservação dos elementos valvares mitrais nos casos de implante de próteses. As próteses foram implantadas com pontos separados em "chuleio", quando houve a necessidade de "acolchoar" possiveis excessos, ou irregularidades do anel valvar. Tal conduta foi adotada nos casos de próteses metálicas, sem que as estruturas valvares interferissem no funcionamento do disco pivotante da prótese. Ao Dr. Sérgio Caminha, a partir de outubro de 1985 , todos os casos de implante de próteses foram realizados com as técnicas descritas de preservação da continuidade entre $o$ anel valvar e a parede ventri- 
ÉVORA, P. R. B.; RIBEIRO, P. J. F.; BRASIL, J. C. F.; OTAVIANO, A. G.; REIS, C. L.; BONGIOVANI, H. L.; BOMBONATO. R.; FEREZ, M. A.; MENARDI, A. C.; SGARBIERI, R. N. - Experiência com dois tipos de técnicas para o tratamento cirúrgico da insuficiência mitral: I. Prótese com preservação de elementos do sistema valvar. II. Plastia valvar com reconstruçăo e avanço da cúspide posterior. Rev. Bras. Cir. Cardiovasc., 3(1): 36-49, 1988.

cular. Entre 1978 e 1985, 45\% dos casos de prótese valvares mitrais eram devidos a lesões do tipo insuficiência. Esta incidência diminuiu para $28 \%$, nos anos de 1986 e 1987. Ao Dr. João Carneiro, aproveito a ocasiăo para prestar a minha homenagem à Disciplina de Cirurgia Torácica e Cardiovascular da Faculdade de Medicina de Ribeirão Preto, onde iniciamos a nossa formação e adquirimos o gosto pela investigação científica. Ressalto, também, que foi trabalhando com o Prof. Carneíro e o Prof. Albert Sader que tomamos contato com a técnica de Sauvage e pudemos "ressuscitá-la", com modificações, no presente. Concordo com o Prof. Car- neiro, quanto ao fato da indicação mais precoce do tratamento cirúrgico das valvopatias mitrais, no sentido da preservação da função ventricular esquerda. Acho muito importante o testemunho de que o processo reumatismal possa comprometer a valva reconstruída. Além disto, a apresentação de um paciente no qual a cirurgia conservadora trouxe bons resultados durante 8 anos pode significar o início de um estudo a médio e longo prazo de tais pacientes. Meus agradecimentos aos três comentadores, pelo enriquecimento da discussão de nosso trabalho, e aos organizadores do $15^{\circ}$. Congresso Nacional de Cirurgia Cardiaca, pela oportunidade de apresentá-lo. 